\title{
Management of Regional Social and Economic Systems
}

\author{
Malakhova L.A. \\ Department of Intercultural Communication and Linguistics \\ Kazan State Institute of Culture \\ Kazan, Russia \\ liliyamalah@mail.ru
}

\author{
Rakhimova G.S. \\ Department Finance and Credit \\ University of management "TISBI" \\ Kazan, Russia \\ guzelrahimova@mail.ru
}

\author{
Malakhov V.P. \\ Department Finance and Credit \\ University of management "TISBI" \\ Kazan, Russia \\ vpmalahov1977@yandex.ru
}

\author{
Korobkova M.A. \\ Department Finance and Credit \\ University of management "TISBI" \\ Kazan, Russia \\ mariakorobkova0106@mail.ru
}

\begin{abstract}
The article deals with the most important elements that make up the management system of social and economic systems of the region. The highest-level managers of medium and large economies pay special attention to long-term planning, setting certain goals, forming ways of action, highlighting the rules and directions of their implementation. They are responsible for these systems' activity effectiveness usage and must plan, target and monitor the activities of regional social and economic systems. The conclusions will facilitate the formation of certain recommendations in the adjustment of the management process. In conducting the study, the authors have tried to link the goals of economic development, the stages of management decisions' formation, taking into account the conditions of modern globalization, transformation of economic systems and their integration with the formation of a certain model of the management process of social and economic systems. Studying the regional economy as a certain object of management it is necessary to take into account the fact that the management of the region at the state level is a kind of system that connects such components as the subject, the object of management and determines the relationship between them.
\end{abstract}

Keywords-regional economy; social and economic systems; management system; management link; management principles; objects and subjects of management.

\section{INTRODUCTION}

In the implementation of the various economic systems' management, the most attention should be paid to the improvement of innovative activity since at present the final results of innovations allow determining the economic power of the subjects of financial and economic activity, the region and the state in the aggregate. In this regard, this issue is the most important, and the direction and pace of future social and economic transformational changes in our country depend on solution of these issues in most cases.

The economic system is a historically formed set of principles in force in a state, rules, legislated norms that determine the forms and content of the most important economic relations that arise in the process of production, distribution, exchange and consumption of economic product [3, p. 63-70].

In modern economic systems, the management process depends on certain conditions due to the specifics of the region, namely: climatic, economic, political, resource, social. In this regard, development of indicative plans for the management of the economic system, the formation of preferences for economic agents, which contributes to the achievement of strategic goals that are set at these stages of economic development; packages of legal acts and legal mechanisms. They regulate the most important principles of economic policy, take place at different levels of management [4].

\section{REVIEW OF LITERATURE}

In the authors ' view, the management process is a complex system consisting of many links, which is manifested in the following provisions:

- the organic unity of the employees, organizational management structure, methods, processes, information and management technology with the critical role of staff;

- close relationship and correlation of the object and subject of management; 


\section{RESULTS}

- a certain condition and the combination of production, technical, economic, social, psychological and legal aspects of management;

- the formation of an integrated approach to the use of technology in the implementation of management process;

- organic unity of quantitative and qualitative methods of analysis and justification of managerial decisions.

\section{RESEARCH METHODOLOGY}

In the implementation of the management process, organizational procedures are developed in accordance with the existing laws. These regularities include compliance of the control system with the objectives, features, status and trends of the management object; the reality of management, which is determined by the presence of objective information resources that allow you to assess the production capabilities properly; objective need of management in specific information; direct connection and feedback of management's object and subject [2, p. 35-39].

Implementing management activities, we can distinguish base processes that remain practically unchanged in form and content. They may be considered as conditionally constant. And those processes that vary depending on the conditions of the external and internal environment. They can be classified as conditional variable [4].

The conditionally constant processes can include a basic set of functions and organizational management structures, management technologies, the presence of objective laws in management, methods of development and implementation of management decisions. As conditional variable ones, we note the presence of certain management principles, methods and techniques of management processes implementation [5,6,7].

With each new process, method or technique, management personnel should consider them from the side of the basic foundations of the existing generally accepted management theory, but if it is revealed that there are no basic principles which can be applied for those innovations, then in most cases they will not confirm their effectiveness.

Most of the various economic systems include three levels of management: upper, middle and lower. The managing staff of each level performs approximately the same functions, where the main ones include the formation of various plans, the implementation of organizational functions, direct management, the development of motivational attitudes of personnel, control. The difference is in the importance they attach to a particular function.

The middle-level management heads departments or divisions within economic systems.

Lower-level managers are the level of officials who manage the activities of their subordinates directly. At this level of management planning and organization functions are implemented in the actions of the manager, who stimulates and directs the activities of employees $[8,9,10,11]$.
In modern conditions, the management theory of economic systems has not sufficiently studied the moment of their activity transition to innovative development. It is necessary to study different aspects that can form the prerequisites for the introduction of various kinds of innovations in the management system with the aim of forming certain dynamics of improving economic systems, identifying a special way that will contribute to solving the most important problems and taking into account the peculiarities of their financial and economic activities.

In modern conditions of market relations' development, innovative activity in the management system should facilitate searching the ways of the most important problems' solving:

- organizing an economic system that is capable of formed and implemented innovative products;

- creating organization and coordination bodies in various stages of innovative activity;

- creating and implementing of practical activities including various elements of the state support, i.e. scientific, technical and innovative work, that ensure the most favorable environment for the fast development of these commercial activities;

- creating and implementing of practical activities' strategies to ensure the safety and development of applied scientific activity;

- laying the groundwork that contributes to the accelerated development of small scientific, technical and innovative entrepreneurship;

- forming a full-fledged infrastructure for innovative products' creation and implementation, which includes a large number of modern innovative enterprises and various funds financing innovative activities;

- introducing a number of measures to modernize the economy based on advanced achievements of science and technology [4].

In this way, the concept proposed by the authors presupposes managing economic systems' studying, as well as implementing their functions in a certain relationship with appropriate analytical procedures for economic activity's results, which contributes to the information clarity of the system's performance results.

When forming and implementing innovative products, and improving managing economic systems, it is necessary to reasonably determine the most important areas in long-term development planning, namely to take into account the increasing level of market competition and economic problems arising during globalization. 
professionalism, which plays a sufficiently important role in the management system.

3. Involve labor team members in the design and use of innovations in the management system. Therefore, it is necessary to define only the most important positions, directions of activity, leaving details to employees. The personnel who design innovations in the management system will feel responsible for the effectiveness of such a solution.

A positive element of the model is the objective, deterministic nature of its action. This is explained by the fact that innovation activity is carried out under the influence of directives and conditions of the management process and the external environment on the basis of implemented strategies, concepts, national projects and programs, each of which has a local range of effective action.

For the governance model to be effective enough to improve innovation, a combination of three main factors is needed:

- impacts on the managed subsystem by the management structures should be based on the achievement of specific goals, directly related to the innovation development programme, which ensure the appropriate quality of the economic system;

- the economic basis of the system, when implementing innovative development, should respond to the relevant management impact;

- the control action must be of a certain size, which must be sufficient to obtain the corresponding effect.

Thus, it is quite important to see the model of the management process when improving innovation in a "contoured -modular" form. This model is significantly distinguished by the fact that it comes into contact with the outside environment quite closely. This fact can be related to the fact that the development of the innovation-based management system is significantly interrelated with the strategies, concepts, national projects, programs and economic systems implemented, where they are directly involved.

\section{CONCLUSIONS}

In today's environment, governance principles are a set of defined rules and norms upon which governance entities rely. The principles of governance are transforming with the changing life of society, and at present the following sufficiently significant principles of regional governance can be distinguished [1]:

1. Shifting of management decision-making center from federal authorities and management to regional bodies and market participants. This principle can be called the principle of decentralization, and the growth of its role in the market economy greatly facilitates the activities of commercial structures in the market economy.

2. The principle of subsidiarity, which allows to speak of the targeted use of funds, which are intended for the implementation of regional projects. This principle can be 


\section{References}

implemented on the basis of a mechanism for financing a minimum volume of State standards for residents of a subject of the Russian Federation.

3. Transition from the formation of regulations from above (vertically) to partnership relations between objects and entities in the field of regional management.

4. The principle of mobility in the field of regional management efficiency, which means that there are stable transformational changes in the field of regional management structure with a significant change in the external environment.

Quite essential, in our view, is the principle of the allocated competence, that is, ensuring the distribution of functions among certain layers of regional management and within them.
[1] Voronin. A.G. Local government: technologies of social and economic growth. SPb., Publishing house of $\mathrm{SPb}$ un-that. 2005.

[2] Raizberg B., Morozov N. State Innovation Process Management. Economist. 2008, 1, pp. 35-39

[3] Startseva O. A., Avakumova N N. Strategy for Transformation of Innovative Development of Regional Economic Systems//National Interests: Priorities and Security. 2008, 10(31), pp. 63-70.

[4] Management of social and economic development of Russia: concepts, goals, mechanisms. M.: Economics. 2002, 702.

[5] Barbakov O. M. The region as an object of management. Sociological researches. 2002, 7 .

[6] Butov V. I., Ignatov V. G., Ketova N. P. Fundamentals of regional economy. M.; Rostov. 2001

[7] Gradov A. P. and others. Regional economy. SPb.: Peter. 2003

[8] Eleneeva Y. Y. Ensuring competitiveness of industrial enterprises. M.: Janus-K. 2001, pp. 274

[9] Ivanov I. G. The regional management. Moscow. 2000

[10] Alexsandr S. Kuznetsov. Russian Professor's meeting. Russian Journal of Physical Education and Sport. 2019, 14(1), pp. 17-22. DOI: 10.14526/2070-4798-2019-14-1-18-24

[11] Kovalenko E. G. The regional economy and management. SPb. 2005. 